\title{
Global monsoon change during the Last Glacial Maximum: a multi-model study
}

\author{
Mi Yan ${ }^{1,2} \cdot$ Bin Wang ${ }^{3,4} \cdot$ Jian Liu $^{1,2}$
}

Received: 29 October 2014 / Accepted: 12 September 2015 / Published online: 26 October 2015

(C) The Author(s) 2015. This article is published with open access at Springerlink.com

\begin{abstract}
Change of global monsoon (GM) during the Last Glacial Maximum (LGM) is investigated using results from the multi-model ensemble of seven coupled climate models participated in the Coupled Model Intercomparison Project Phase 5. The GM changes during LGM are identified by comparison of the results from the pre-industrial control run and the LGM run. The results show (1) the annual mean GM precipitation and GM domain are reduced by about 10 and $5 \%$, respectively; (2) the monsoon intensity (demonstrated by the local summer-minus-winter precipitation) is also weakened over most monsoon regions except Australian monsoon; (3) the monsoon precipitation is reduced more during the local summer than winter; (4) distinct from all other regional monsoons, the Australian monsoon is strengthened and the monsoon area is enlarged. Four major factors contribute to these changes. The lower greenhouse gas concentration and the presence of the ice sheets decrease air temperature and water vapor content,
\end{abstract}

Jian Liu

jliu@njnu.edu.cn

1 Key Laboratory of Virtual Geographic Environment of Ministry of Education and State Key Laboratory Cultivation Base of Geographic Environment Evolution of Jiangsu Province, School of Geography Science, Nanjing Normal University, 1 Wenyuan Road, Nanjing 210023, China

2 Jiangsu Center for Collaborative Innovation in Geographical Information Resource Development and Application, Nanjing 210023, China

3 Department of Atmospheric Sciences, International Pacific Research Center, University of Hawaii at Manoa, Honolulu, HI 96825, USA

4 Earth System Modeling Center, Nanjing University of Information Science and Technology, Nanjing 210044, China resulting in a general weakening of the GM precipitation and reduction of GM domain. The reduced hemispheric difference in seasonal variation of insolation may contribute to the weakened GM intensity. The changed land-ocean configuration in the vicinity of the Maritime Continent, along with the presence of the ice sheets and lower greenhouse gas concentration, result in strengthened land-ocean and North-South hemispheric thermal contrasts, leading to the unique strengthened Australian monsoon. Although some of the results are consistent with the proxy data, uncertainties remain in different models. More comparison is needed between proxy data and model experiments to better understand the changes of the GM during the LGM.

Keywords Global monsoon - Last Glacial Maximum • External forcing $\cdot$ CMIP5 $\cdot$ PMIP3

\section{Introduction}

Objectives of the Paleoclimate Modeling Intercomparison Project Phase 3 (PMIP3) are to understand the mechanisms of past climate changes and to test the capability of the models used for future climate projections to represent a climate different from the modern one (Braconnot et al. 2011). Three key time periods of PMIP3 (the Last Glacial Maximum (LGM), mid-Holocene, and Last Millennium) are now included in the Coupled Model Intercomparison Project Phase 5 (CMIP5) within Tier 1 and Tier 2 (Taylor et al. 2012). Simulating the LGM provides an opportunity to study climate response to a decrease in $\mathrm{CO}_{2}$ concentration and an increase in ice sheets over North America and northern Europe, along with the change of the solar irradiance and the land-sea mask. Researchers have investigated regional (Yanase and Abe-Ouchi 2007; Jiang and Lang 
2010), hemispheric (Li and Battisti 2008; Laine et al. 2009; Rojas et al. 2009; Chavaillaz et al. 2013; Rojas 2013) and general climatologic features (Braconnot et al. 2007a, b; Otto-Bliesner et al. 2009; Wang et al. (2013b)) responding to the LGM conditions using the PMIP datasets. However, little has been done concerning the changes of the monsoon precipitation during the LGM, especially in the global perspectives.

Global monsoon (GM) represents the dominant mode of annual variation of the Earth's climate system (Wang and Ding 2008). Study of GM change can advance the understanding of the processes by which the coupled climate system responds to various external forcings. Kim et al. (2008) emphasized the response of the GM precipitation to volcanic aerosols. Wang et al. (2012) found that regional monsoons are coordinated not only by external solar forcing but also by internal feedbacks. It was also found that the Northern Hemisphere summer monsoon (NHSM) intensification is primarily attributed to a Mega-ENSO and the Atlantic Multidecadal Oscillation (AMO), and further influenced by hemispherical asymmetric global warming (Wang et al. 2013a). Liu et al. (2009) examined how the GM precipitation respond to the external and anthropogenic forcing during the last millennium and further investigated mechanisms governing decadal-centennial variations of the global summer monsoon precipitation (Liu et al. 2012). An important finding is that the NHSM precipitation is enhanced by the increased NH land-ocean thermal contrast and hemispheric thermal contrast and it responds to greenhouse gas forcing more sensitively than Southern Hemisphere summer monsoon (SHSM) precipitation, whereas the SHSM precipitation responds to the solar-volcanic radiative forcing more sensitively than the NHSM precipitation.

The changes of the modern and the future monsoon under global warming have been investigated using the observations and models. The global land monsoon precipitation is found to be weakened in the past half century (Wang and Ding 2006; Zhou et al. 2008a; Li et al. 2010), but has seen no significant trend since 1980 despite the rapid intensification of global warming (Zhou et al. 2008b). On the other hand, the total global monsoon precipitation (over both land and ocean) shows increasing trends over the period of 1979-2008. The future change of the GM precipitation and intensity has been investigated (Kitoh et al. 2013; Christensen et al. 2013; Hsu et al. 2013; Chen and Sun 2013; Lee and Wang 2014) using the Representative Concentration Pathways scenarios (RCP4.5 and/or RCP 8.5 ) for 2006-2100 as projected by models participated in CMIP5. The results show that the GM precipitation will increase over most parts of the GM regions due to the moisture convergence increase, but whether the GM domain will expand or not is inconsistent within these works.
The climate during LGM is quite opposite to the global warming, which can provide a test for the models used to predict future change. Proxy data revealed a stronger East Asian winter monsoon but weaker summer monsoon during glacial periods (Jiang and Lang 2010; Wang 2009). Chabangborn et al. (2014) found that paleo-data and climate model simulation were agreed in a dry LGM climate in the western and northern part of the Asian monsoon region due to a stronger winter monsoon, and/or wetter conditions in equatorial areas of the Asian monsoon region due to a strengthened summer monsoon. However, the sparse reconstruction data in the global monsoon region make it difficult to pin down the uncertainty. The LGM experiments conducted by CMIP5/PMIP3 provide us another way to find out how the GM responds to the changes of external forcing.

Previous works have shown that large uncertainties exist in simulation of the past and future climate change. Some results are model dependent. For instance, Jiang and Lang (2010) found that the East Asian winter monsoon strengthened during the LGM in 10 out of 21 models but weakened in the other 11 models used in PMIP2. Xiang et al. found that some models projected a strengthened Equatorial Pacific trade wind while others projected a weakened one in the future using CMIP5 future change simulations (personal communication). In CMIP5/PMIP3, most models have been upgraded from atmosphere-ocean coupled model (AOGCM) to the Earth System Models (ESM), containing more complex processes than those in PMIP2 models. Harrison et al. (2014) compared PMIP2 and CMIP5/ PMIP3 simulations with the reconstructions and found that some models perform better than others. It suggests a careful evaluation of individual model and the Multi-Model Ensemble (MME) are necessary in analyzing the model results.

In the present work, we use the simulated results from 7 coupled models participated in the CMIP5/PMIP3 to investigate the characteristics of GM precipitation change under the LGM boundary conditions, and explore the possible causes of the changes. The models and data used in this study are introduced in Sect. 2. Section 3 evaluates the models' performance. The analyses and results are shown in Sect. 4. The possible attributions of GM change in the LGM are discussed and concluded in Sect. 5.

\section{Model, data and analysis method}

\subsection{Models and experiments}

Among the models participated in CMIP5, only 8 models have finished two PMIP3 experiments for the pre-industrial control (piControl) and the LGM so far. Because of lacking 
Table 1 CMIP5/PMIP3 models and experiments used in this study

\begin{tabular}{|c|c|c|c|c|}
\hline Model & Institution & $\begin{array}{l}0 \text { ka piControl } \\
\text { Time span (years) }\end{array}$ & $\begin{array}{l}21 \text { ka LGM } \\
\text { Time span (years) }\end{array}$ & $\begin{array}{c}\text { AGCM resolution } \\
\text { Lat } \times \text { Lon Grids }\end{array}$ \\
\hline CCSM4 & $\begin{array}{l}\text { National Centre for Atmospheric Research } \\
\text { (NCAR) }\end{array}$ & 501 & 101 & $288 \times 192$ \\
\hline CNRM-CM5 & $\begin{array}{l}\text { Centre National de Recherches } \\
\text { Meteorologiques/Centre Europeen de } \\
\text { Recherche et Formation Avancees en } \\
\text { Calcul Scientifique (CNRM-CERFACS) }\end{array}$ & 850 & 200 & $256 \times 128$ \\
\hline GISS-E2-R & $\begin{array}{l}\text { NASA Goddard Institute for Space Studies } \\
\text { (NASA GISS) }\end{array}$ & 1200 & 100 & $144 \times 90$ \\
\hline IPSL-CM5A-LR & Institute Pierre-Simon Laplace (IPSL) & 1000 & 200 & $96 \times 95$ \\
\hline MIROC-ESM & $\begin{array}{l}\text { Atmosphere and Ocean Research Institute } \\
\text { (University of Tokyo), National Institute } \\
\text { for Environmental studies, and Japan } \\
\text { Agency for Marine-Earth Science and } \\
\text { Technology (MIROC) }\end{array}$ & 531 & 100 & $128 \times 64$ \\
\hline MPI-ESM-P & $\begin{array}{l}\text { Max Planck Institute for Meteorology } \\
\text { (MPI-M) }\end{array}$ & 1156 & 100 & $196 \times 98$ \\
\hline MRI-CGCM3 & Meteorological Research Institute (MRI) & 500 & 100 & $320 \times 160$ \\
\hline
\end{tabular}

Table 2 Comparison of boundary conditions for the piControl and LGM experiments

\begin{tabular}{lll}
\hline & piControl & LGM \\
\hline Orbital parameters & $\begin{array}{c}\text { Eccentricity }=0.016724 ; \text { obliquity }=23.446^{\circ} ; \text { angular } \\
\text { precession }=102.04^{\circ}\end{array}$ & $\begin{array}{c}\text { Eccentricity }=0.018994 ; \text { obliquity }=22.949^{\circ} \text {; angular pre- } \\
\text { cession }=114.42^{\circ}\end{array}$ \\
Trace gases & $\mathrm{CO}_{2}=280 \mathrm{ppm} ; \mathrm{CH}_{4}=650 \mathrm{ppb} ; \mathrm{N}_{2} \mathrm{O}=270 \mathrm{ppb}$ (around & $\mathrm{CO}_{2}=185 \mathrm{ppm} ; \mathrm{CH}_{4}=350 \mathrm{ppb} ; \mathrm{N}_{2} \mathrm{O}=200 \mathrm{ppb}$ \\
& A. D. 1750) & Provided by ICE-6G v2 (Peltier 2009) \\
Ice sheets & Modern & Provided by PMIP3 \\
Land-sea mask & Modern &
\end{tabular}

of sea surface temperature (SST) output, FGOALS-g2 is excluded in this study. The results from 7-model piControl and LGM experiments are investigated. The models and experiments used in the study are listed in Table 1. The piControl ( $0 \mathrm{ka})$ is used to evaluate the models' performance and serve as the benchmark for comparing with the LGM.

The boundary conditions (the orbital parameters, the trace gases, the ice-sheet and the land-sea mask) for the LGM experiment are listed and illustrated in Table 2 and Fig. 1. The insolation (viz. incident shortwave radiation at the top of the atmosphere) is also different from the piControl experiment (Fig. 2; http://pmip2.lsce.ipsl.fr/pmip2/ design/tables/inso_tables_21k.shtml). More information can be found on the PMIP3 website (http://pmip3.1sce.ipsl. $\mathrm{fr} /$ ) and in Braconnot et al. $(2011,2012)$.

To validate the model performance, each model's output is interpolated into a fixed $2.5^{\circ}$ (latitude) $\times 2.5^{\circ}$ (longitude) grid using bilinear interpolation method. The MME of the 7 models (7MME) is constructed by

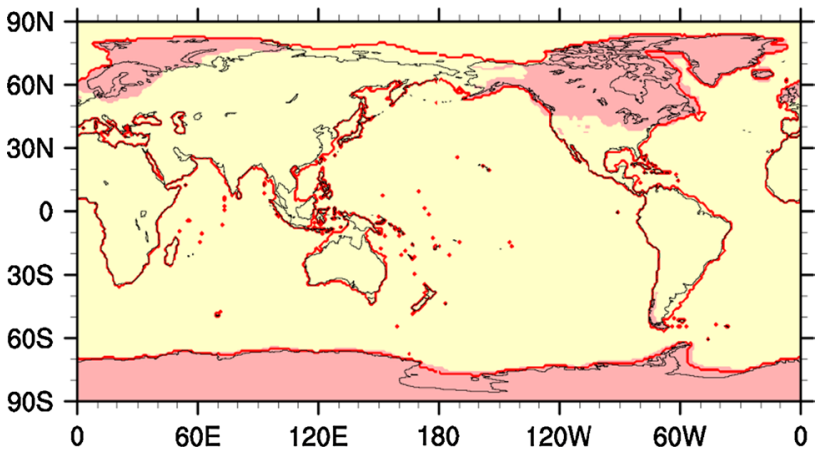

Fig. 1 Distributions of the land-sea mask and land-ice during the LGM. The land-sea mask during the LGM is in red contour, the land ice-sheet is color-shaded

arithmetic mean. Model climatology is obtained from the last 500 model years of each model for the piControl experiment and from the last 100 model years for the LGM experiment. 


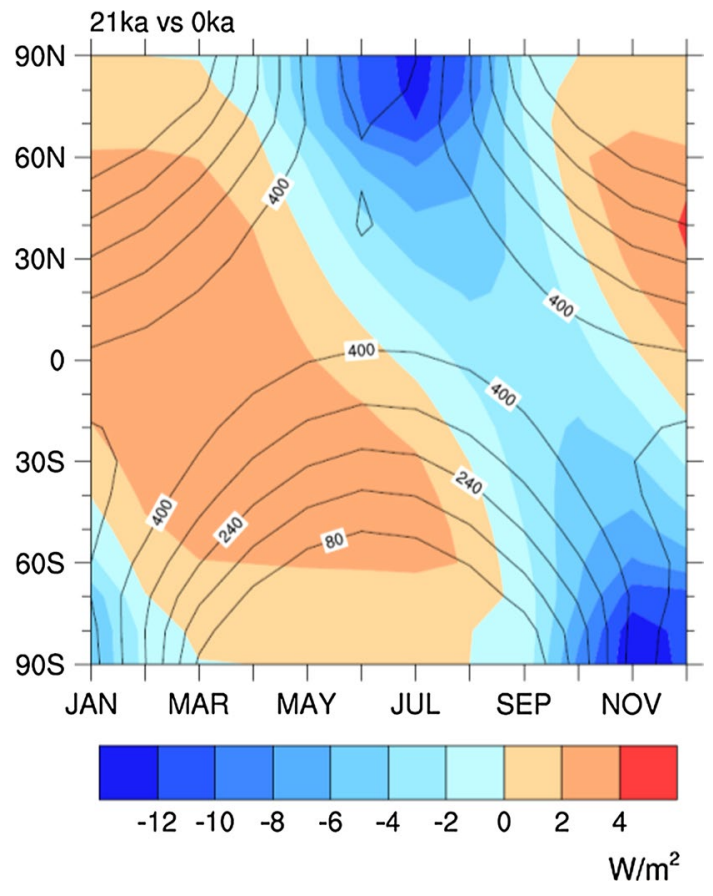

Fig. 2 Change of the insolation during LGM. The insolation during piControl is plotted in contours, and the difference between the LGM and the piControl is color-shaded (units in $\mathrm{Wm}^{-2}$ )

\subsection{Data}

The Climate Prediction Center Merged Analysis of Precipitation (CMAP) data (Xie and Arkin 1997) and the Global Precipitation Climatology Project (GPCP) data (Huffman et al. 2009) from 1979 to 2010 are merged by arithmetic mean to serve as the observation data (Lee and Wang 2014). The reason to merge the CMAP and GPCP data sets is to diminish the uncertainty of the individual dataset. Meanwhile, the difference between the CMAP and the GPCP is not significant in terms of climatology. As Lee and Wang (2014) found that the pattern correlation coefficient (PCC) between CMAP and GPCP climatology is 0.95, $0.94,0.95,0.96$ and 0.96 , respectively for annual mean, March-April-May (MAM), June-July-August (JJA), September-October-November (SON), and December-January-February (DJF) seasonal mean precipitation.

The merged precipitation data is also on a fixed $2.5^{\circ}$ (latitude) $\times 2.5^{\circ}$ (longitude) grid. The observed climatology is obtained from the 32-year (1979-2010) data.

\subsection{Method}

The PCC and normalized root-mean-square-error (NRMSE) between the simulation and observation are used to objectively evaluate the performance of the models. The NRMSE is the RMSE normalized by the observed standard deviation that is calculated with reference to the global mean (Lee and Wang 2014).

The signal-to-noise $(\mathrm{S} 2 \mathrm{~N})$ ratio is used for the sake of depicting significant changes. In this study, the $\mathrm{S} 2 \mathrm{~N}$ ratio is defined by the ratio of the absolute mean of the 7MME (as the signal) to the averaged absolute deviation of the individual model against the 7MME (as the noise). Only the areas where the $\mathrm{S} 2 \mathrm{~N}$ ratio exceeds 1 are discussed in the following sections.

\section{Model evaluations}

\subsection{Annual cycle of precipitation}

Wang and Ding (2008) defined two annual cycle (AC) modes of the precipitation according to the EOF analysis of the climatological monthly mean precipitation. The first EOF mode (AC1), representing a solstice global monsoon mode, can be well explained by the difference between June-July-August-September (JJAS) and December-January-February-March (DJFM) mean precipitation. The second EOF mode (AC2), representing an equinox asymmetric mode, can be represented by the difference between April-May (AM) and October-November (ON) mean precipitation. Therefore, in this study, these two AC modes will be evaluated. To depict the monsoon mode (AC1) over the Northern Hemisphere (NH) and the SH separately, the annual range (AR) is used, which is calculated by the difference between the local summer rainfall and local winter rainfall at each location, i.e., JJAS (DJFM) mean precipitation minus DJFM (JJAS) mean precipitation for the NH (SH).

Figure $3 \mathrm{a}, \mathrm{b}$ show the spatial distribution patterns of the $\mathrm{AR}$ and the $\mathrm{AC} 2$ derived from the 7MME of piControl runs and the merged CMAP-GPCP. Although the models underestimated the AR over the western Pacific and overestimated the AC2 over the Indian Ocean and southern Pacific, they depict well the general patterns of the AR and $A C 2$, especially the AR. The PCC and NRMSE of the AR (AC2) between 7MME simulation and observation are $0.87(0.79)$ and 0.52 (0.72). The individual model's PCC and NRMSE for the AR are ranged from 0.72 to 0.83 and from 0.61 to 0.95. For the $\mathrm{AC} 2$, the individual $\mathrm{PCC}$ and NRMSE are ranged from 0.59 to 0.73 and from 0.84 to 1.28 (Fig. 4a, b).

\subsection{Global monsoon precipitation intensity and domain}

The ratio of the local AR over the annual mean precipitation is used to demonstrate the GM precipitation intensity (Wang and Ding 2008). This ratio reflects how large is the seasonal variation of the precipitation compared with its annual mean. The GM precipitation domain is defined by 
(a) Annual range (7MME)
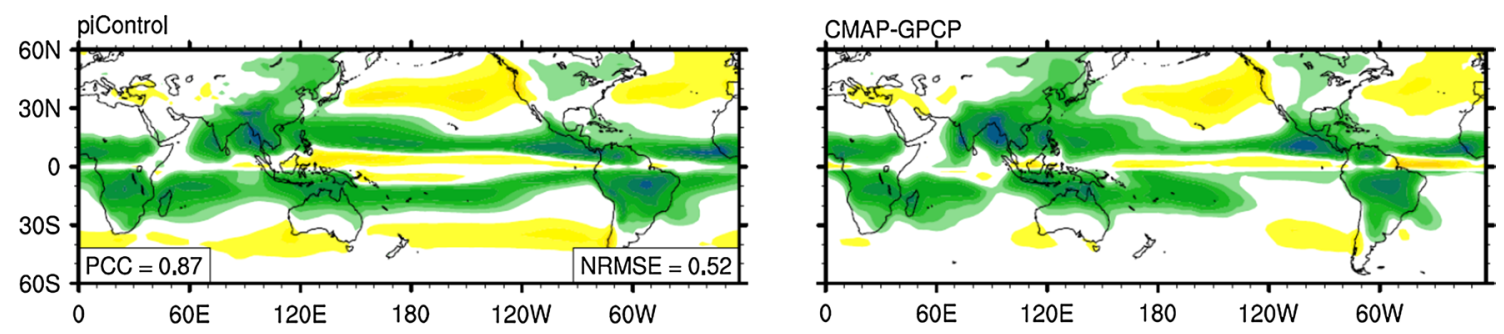

(b) The second annual cycle (7MME)

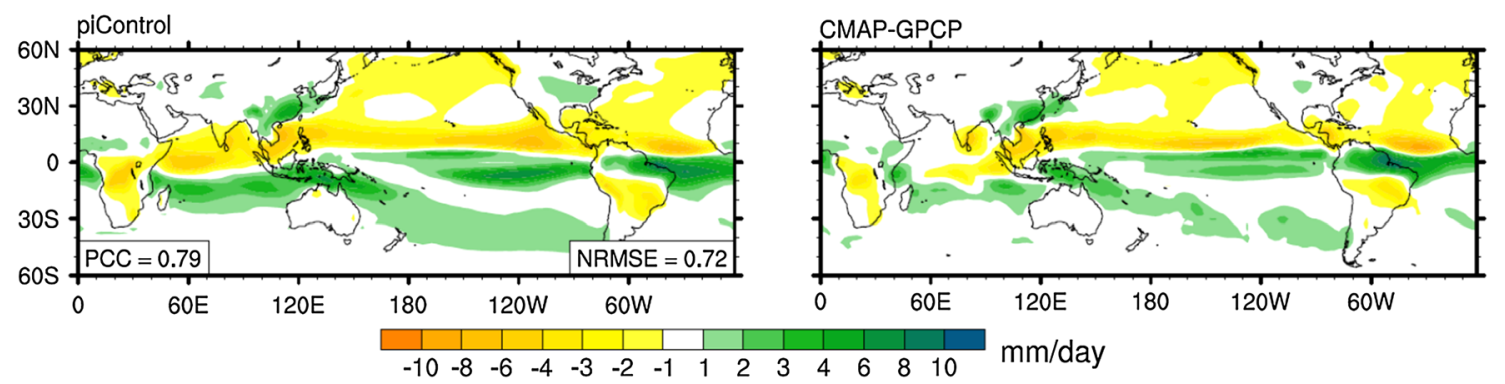

(c) GM precipitation intensity and domain (7MME)

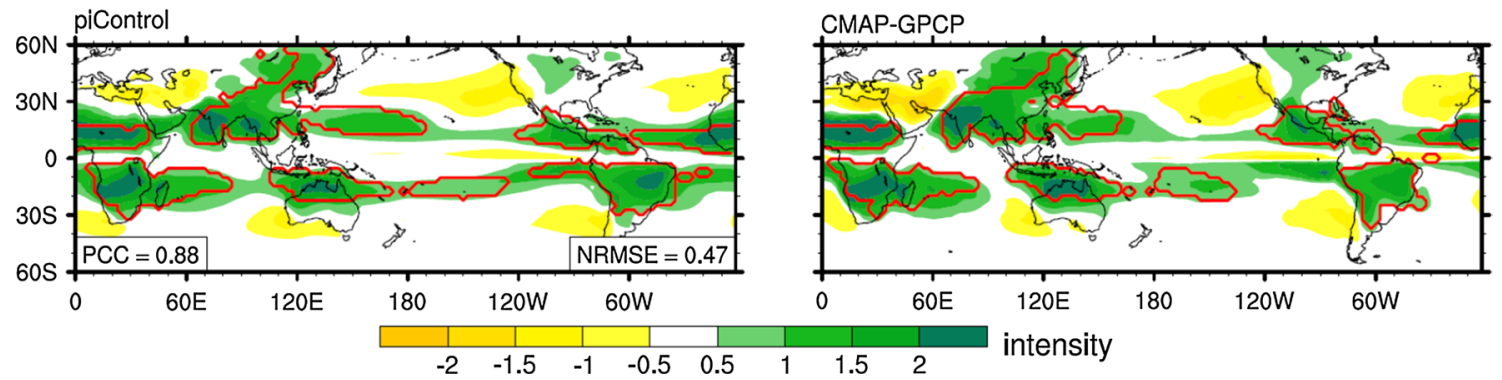

Fig. 3 Comparison of precipitation climatology between 7MME (left panels) and observation (the merged CMAP-GPCP) (right panels): a the annual range (JJAS minus DJFM for Northern Hemisphere, DJFM minus JJAS for Southern Hemisphere), b the second annual cycle mode (AC2, equinoctial asymmetric mode, AM minus $\mathrm{ON}$ ),

the regions where the local AR exceeds $2.5 \mathrm{~mm} /$ day and the GM precipitation intensity exceeds 0.55 (Wang et al. 2011).

The 7MME captures the monsoon precipitation intensity realistically (Fig. 3c). The PCC and NRMSE of the GM precipitation intensity between $7 \mathrm{MME}$ and the observation are 0.88 and 0.47 , much better than the individual models, whose PCC and NRMSE are from 0.78 to 0.84 and from 0.56 to 0.69 (Fig. 4c). To evaluate the models' performance on the monsoon precipitation domains, the threat score is used, which is defined as the number of hit grids divided by the sum of hit, missed, and false-alarm grids (Wang et al. 2011). The threat score of $7 \mathrm{MME}$ is 0.64 , still higher than those of the individual models, which are ranged from 0.44 to 0.56 . The main differences between the simulation and and $\mathbf{c}$ global monsoon precipitation intensity and domain. The numbers in the lower-left and lower-right corners in the left panels indicate pattern correlation coefficient (PCC) and normalized root-meansquare-error (NRMSE) between the simulated and observed global precipitation

the observation are found over East Asia, Northwest Pacific and South American monsoon regions.

Lee and Wang (2014) evaluated the historical run period of 1980-2005 derived from the 20 CGCMs' MME participated in the CMIP5. They also found that the simulated monsoon precipitation intensity and domain did not match the observed well over the Western North Pacific-East Asia monsoon region. The disagreement over these regions seems to be a common problem in the state-of-the-art general climate models. It might be related to the difficulty in correctly simulate the annual march of the western North pacific Subtropical high and the treatment of processes related to Tibetan Plateau in the models.

As the 7MME best captures the observed characteristics of the $\mathrm{AR}, \mathrm{AC} 2$, GM precipitation intensity and domain, we 
(a) the annual range

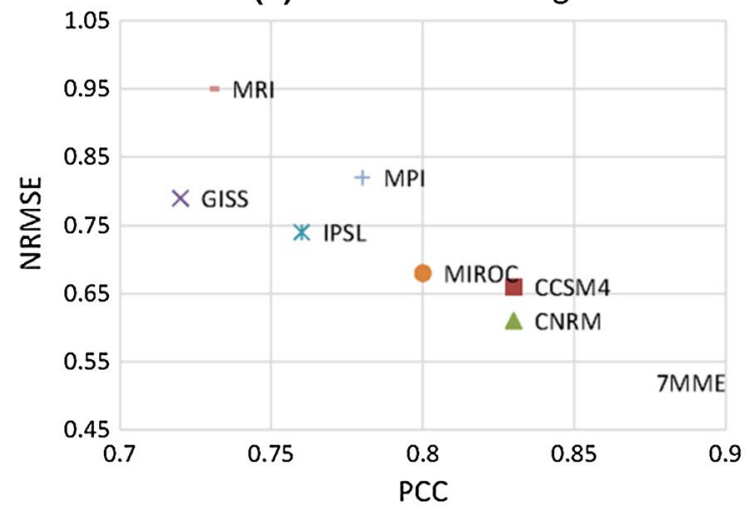

(c) GM precipitation intensity

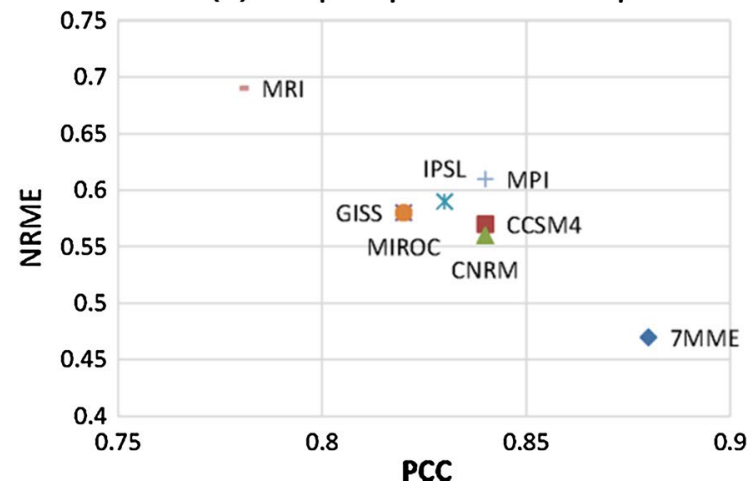

(b) the second annual cycle

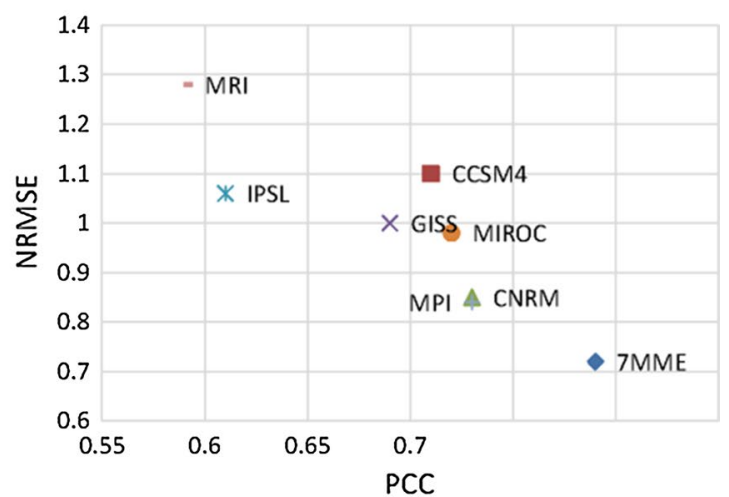

Fig. 4 Models' performance on simulating the GM precipitation climatology: a annual range (AR), b the second mode of annual cycle (AC2), and $\mathbf{c}$ GM precipitation intensity. The abscissa and ordinates are PCC and NRMSE, respectively

will investigate the changes of the GM precipitation during the LGM mainly based on the 7MME in the following sections. Additional information from individual models is provided when needed to discuss the robustness of the changes.

\section{GM changes during LGM}

Before examination of the GM change, we briefly discuss the global mean temperature and precipitation changes as a background for understanding the GM changes. The $7 \mathrm{MME}$ results indicate that during LGM, the global mean surface air temperature was reduced by $4.43{ }^{\circ} \mathrm{C}$ compared to preindustrial period. The decreases of global mean temperature is primarily caused by lower greenhouse gas concentration and the presence of ice sheets because the annual mean insolation is nearly the same. The decrease in temperature dramatically reduced the atmospheric saturation water vapor content according to the Clausius-Clapeyron equation, and thus the total atmospheric moisture content decreased. As a result, the annual mean global precipitation rate during LGM decreased with a rate of $2.26 \%$ per degree of global cooling. We note that the CMIP5 model assessment indicates that the global mean precipitation will increase by $1.9 \%$ per degree global mean temperature rise. The rate of the change of global precipitation is slightly higher under the LGM cooling than under the global warming scenario. But this difference may not be statistically significant and could be due to different MME models. A rigorous comparison should use the same group of models' MME which is not available.

In comparison, the area averaged annual mean GM precipitation rate is $3.66 \mathrm{~mm} /$ day in the present day and $3.30 \mathrm{~mm} /$ day during the LGM. There is a reduction of rainfall rate of $0.36 \mathrm{~mm} /$ day in LGM or $9.84 \%$ decrease of the GM precipitation rate. Given the global mean surface air temperature reduction of $4.43{ }^{\circ} \mathrm{C}$, it means the decrease of GM precipitation rate is $2.22 \%$ per degree of global cooling. This rate of change is essentially the same as that of the global mean precipitation.

Given this overall picture, in the following subsections we shall further discuss the GM changes in terms of the domain (4.1), intensity (4.2) and seasonal distribution (4.3) as well as the change of Australian monsoon that is unique due to change of the land-ocean configuration accompanied by decreased sea level during LGM. 


\subsection{Global monsoon domain change}

The ensemble mean GM domain is reduced over most monsoon regions except Australian monsoon (Fig. 5). The total global monsoon area is reduced by $5.5 \%$ during the LGM, the NH monsoon area reduced by $7.3 \%$ and the SH monsoon area reduced by $3.4 \%$ (Table 3). The reduction of global and $\mathrm{NH}$ monsoon areas are consistent across individual models (Fig. 6). However, the reduction of the SH monsoon domain area has large spread among individual models, thus inconclusive. The changes of the sub-monsoon areas over the $\mathrm{SH}$ are much larger than those over the NH (Fig. 6; Table 3).

For the NH, the sub-monsoon areas are reduced 8.7, 7.3 and $4.3 \%$ over Asia, northern Africa and North America, respectively. In addition, the Asian and North American monsoon domain are shifted southeastward, especially their northwest ridges. Six models have simulated the shifting except MRI-CGCM3. The shift of the Asian monsoon domain is consistent with the palaeo-data (Chabangborn et al. 2014) and opposite to the simulated northward shift of the Asian summer monsoon circulation under $\mathrm{CO}_{2}$ doubling (Kitoh et al. 1997). Braconnot et al. (2007b) also found that some of the models participated in PMIP2 simulated a southward shift of the intertropical convergence zone (ITCZ) over the continents and the Indian Ocean, which was in agreement with the results found from marine data (Leduc et al. 2007). Since the ITCZ in monsoon region is referred to as a monsoon trough, the shift of the ITCZ is consistent with the shift of the monsoon domain. Theoretically, the ITCZ always tends to shift toward the warmer ocean. During the LGM, the SST is decreased more over the mid-high latitudes than over the tropics (Fig. 7), and more over the northern tropics than over the southern

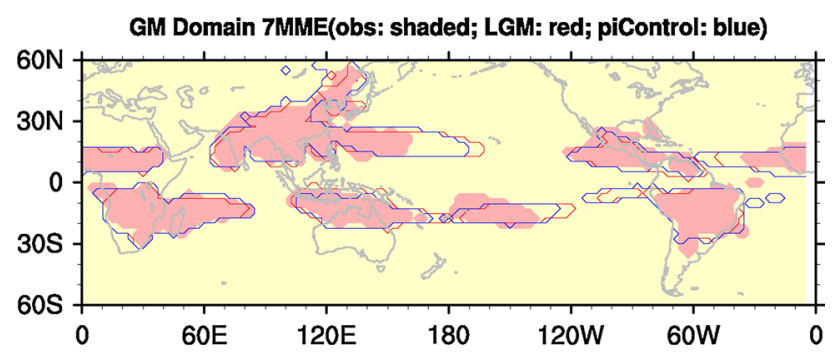

Fig. 5 Changes of the GM domain. The GM domain derived from the merged CMAP-GPCP is color-shaded. The simulated GM domain in the piControl run and the LGM run is indicated by blue and red lines, respectively tropics. The southern tropical ocean is a little warmer than the northern tropical ocean, which favors the southward shift of the ITCZ. In addition, there is no La Nina or El Nino like signal during the LGM, which is also not clear in the PMIP2 simulations (DiNezio et al. 2011).

For the SH, the changes of sub-monsoon domain are inhomogeneous. The South America and southern Africa monsoon domains are reduced by 15.6 and $13.4 \%$, respectively, while the Australian monsoon domain is dramatically enlarged by $36.4 \%$. All the models simulate the shrink of the South American monsoon domain. The results of the most models, except the CNRM-CM5 and MPI-ESM-P, are agreed in the reduced South African monsoon domain. The enlargement of the Australian monsoon domain is simulated by most models except MPI-ESM-P (Fig. 6).

The smaller changes of NH monsoon domain in LGM may be partially related to the fact that the domains tend to shift southeastward due to the cooling effects of the two ice sheets located over the NH high latitude (Fig. 1). The shrink of the total domain area may primarily due to the global cooling and reduction of moisture availability induced by the lower greenhouse gas concentration, as well as the reduced insolation during summer and increased insolation during winter (Fig. 2). The radiative forcing does not change the annual mean GM but tends to reduce the AR of the NH monsoon due to seasonal redistribution of insolation associated with the precession cycle. On the other hand, there are no shifting in the SH sub-monsoons. The shrink of the southern African and South American monsoon domain is likely due to a combination of the cooling associated with the reduced greenhouse gas concentration and the reduced $\mathrm{AR}$ in insolation. In the ocean-dominant $\mathrm{SH}$, the monsoon is more sensitive to the reduction of moisture content due to global cooling. The drastically enlarged Australian monsoon domain, as will be discussed in 4.4 , might be ascribed to the expanded land area and the strengthened seasonal landocean thermal contrast and $\mathrm{NH}-\mathrm{SH}$ thermal contrast.

\subsection{Global monsoon intensity change}

The monsoon intensity measured by the annual range and/or the amount of local summer rainfall indicates weakening monsoons over Asian, northern African, North and South American, and the northern part of southern African monsoon regions, whilst a strengthening occurring over Australian monsoon region, a small area in subtropical East Asia, and far southern African

Table 3 Changes of the GM and sub-monsoon areas

\begin{tabular}{llllllll}
\hline Monsoon regions & Global & North African & Asian & North American & Southern African & Australian & South American \\
\hline Changed area (\%) & -5.53 & -7.34 & -8.68 & -4.26 & -13.44 & 36.36 & -15.63 \\
\hline
\end{tabular}




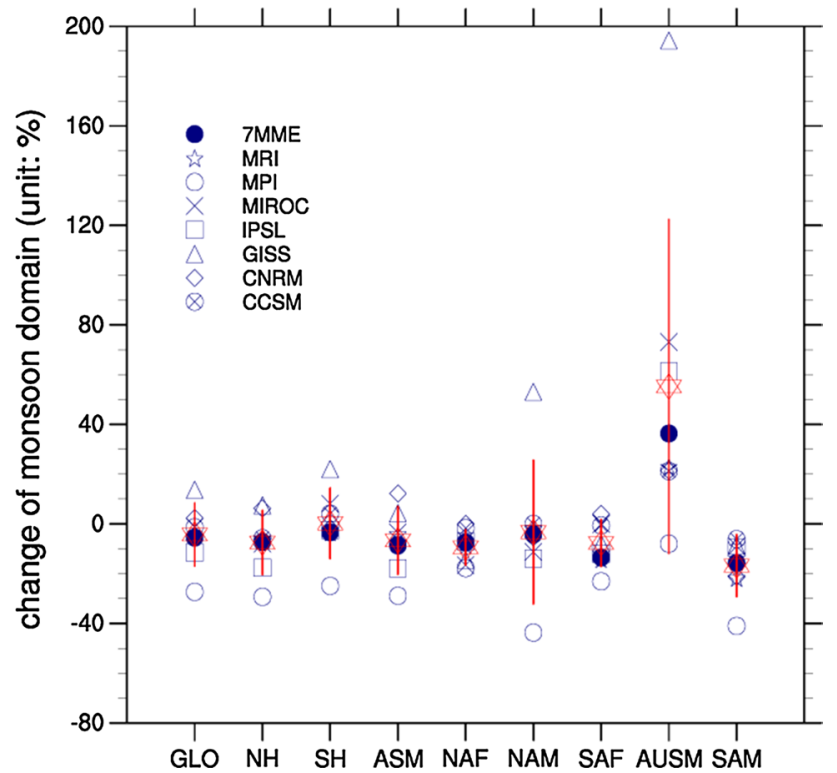

Fig. 6 Changes of the monsoon domain area (\%), including global (GLO), NH, SH, Asian (ASM), North African (NAF), North American (NAM), South African (SAF), Australian (AUSM) and South American (SAM), derived from the individual models and the 7MME. The results from the CCSM4, the CNRM-CM5, the GISSE2-R, the IPSL-CM5A-LR, the MIROC-ESM, the MPI-ESM-P, the MRI-CGCM3 and the 7MME are in circle with cross, diamond, upward triangle, hollow square, cross, circle, 5-point star and filled circle, respectively. The 6-point stars in red with red line indicates the mean values of the seven models and their standard deviation

monsoon region (Fig. 8). The monsoon region used here and after refers to the fixed present day monsoon region. The annual mean precipitation shows similar changes as the summer monsoon precipitation over most monsoon regions except the Australian monsoon region. The annual mean precipitation over the northern Australia is slightly reduced in spite of the Australian summer monsoon intensified. This means that Australian monsoon precipitation is reduced in other seasons than local summer. Despite the outliers, the area averaged annual range derived from the 7MME and models are decreased over the global, the $\mathrm{NH}$ and most regional monsoon areas except the Australian monsoon region, which is increased on the contrary (Fig. 9).

The reduced annual ranges over all $\mathrm{NH}$ monsoon regions are mainly due to the decreasing JJAS mean precipitation, i.e. the boreal summer precipitation is decreased much more than the boreal winter counterparts (Fig. 10a, b). The precipitation over South American and northern part of the Southern African monsoon regions is decreased in DJFM (austral summer) while increased in JJAS (austral winter), which leads to the reduction of the annual range over these two monsoon regions. This change may be caused by the changes in the annual distribution of insolation. On the contrary, for the Australian and far southern African monsoon regions, the annual range are increased during the LGM, as a consequence of the wetter austral summer and drier austral winter (Fig. 10). This indicates the change of the local summer rainfall plays important role in the change of the annual range.

In addition, the precipitation over the Northern Australia is only increased in DJF while decreased in the other three seasons (not shown), which explains why the annual mean precipitation over this region is slightly decreased while the annual range is increased.

\subsection{The change of the seasonal distribution of global monsoon}

The variation of GM precipitation computed here is also based on the fixed present day monsoon domain.

\section{(a) DJF mean SST}

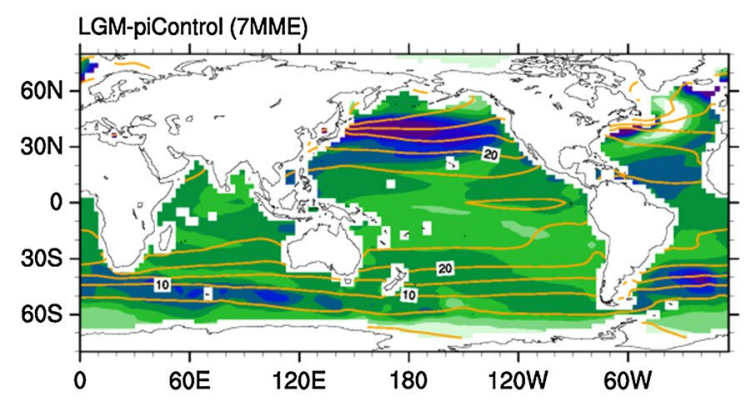

(b) JJA mean SST

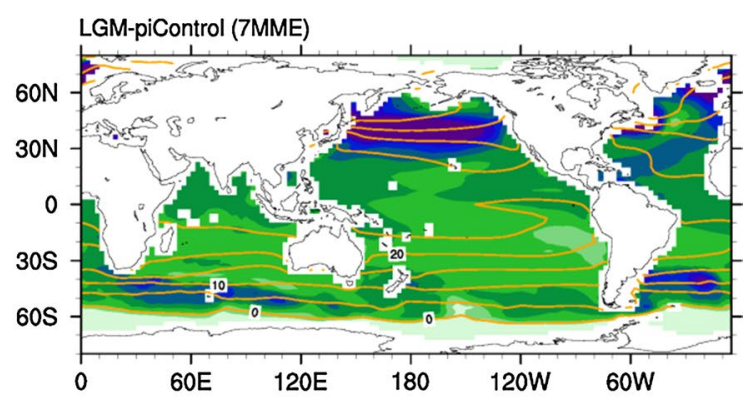

$$
\begin{array}{lllllllll}
-4 & -3.5 & -3 & -2.5 & -2 & -1.5 & -1 & { }^{\circ} \mathrm{C}
\end{array}
$$

Fig. 7 Changes of the DJF (a) and JJA (b) mean sea surface temperature (SST). The difference between LGM and piControl is color-shaded, the climatology of piControl is in contour. Only the areas where the S2N ratio exceeds 1 are plotted 
(a) annual range

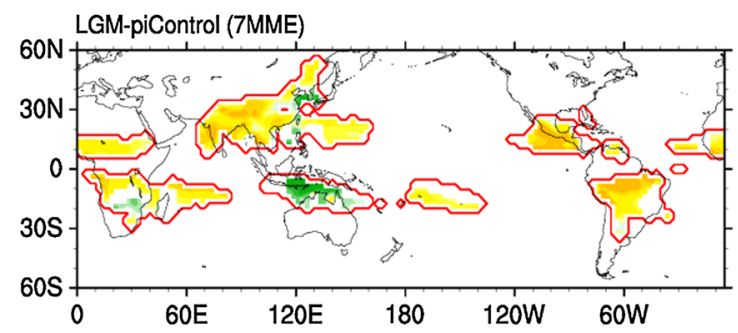

(b) local summer rainfall

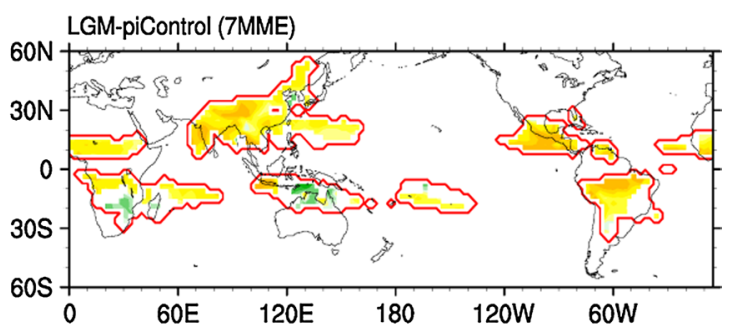

(c) annual mean rainfall

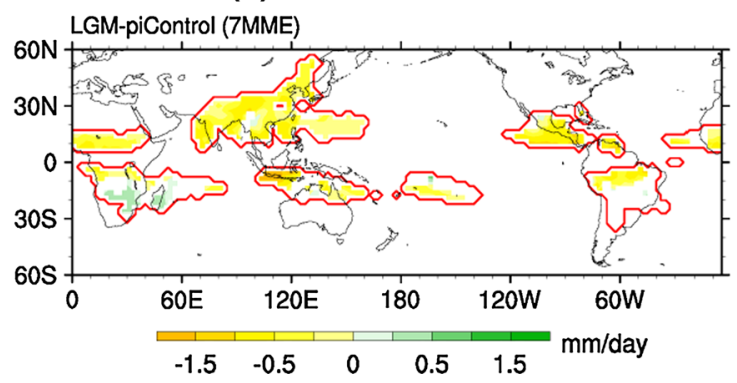

Fig. 8 Changed global monsoon intensity measured by a the annual range, b local summer rainfall, and $\mathbf{c}$ annual mean precipitation. The contour in red denotes the GM domain derived from the merged CMAP-GPCP data

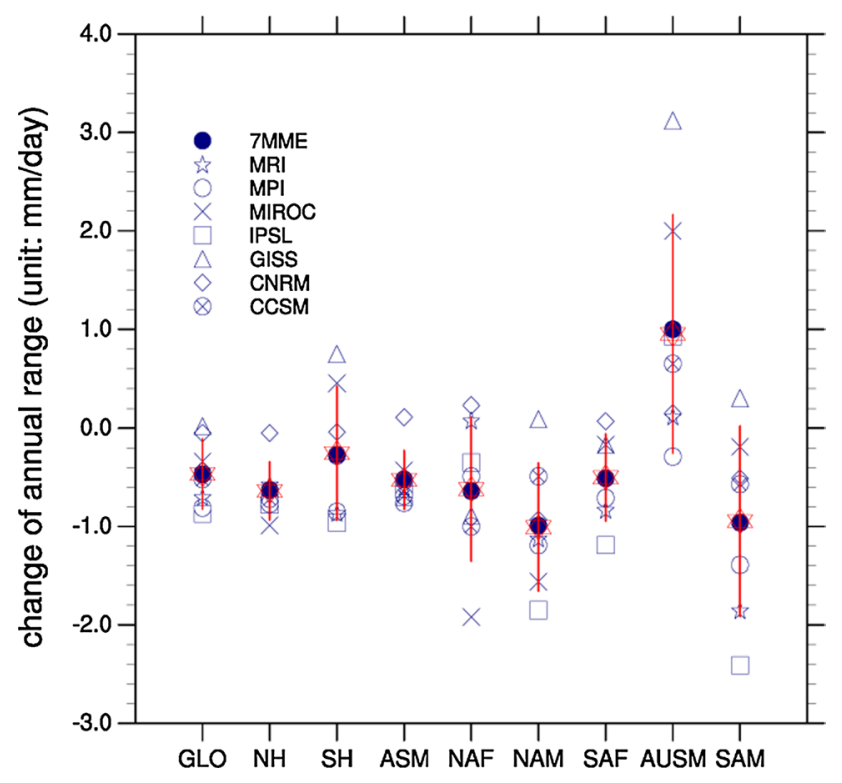

Fig. 9 Same as Fig. 6, but for the changes of annual range in different area

While the annual mean GM precipitation is reduced due to decreased greenhouse gas forcing and the existence of ice sheets, the reduction of the GM precipitation shows obvious seasonal variation. The GM precipitation is reduced more from May to September, and less from November to March (Fig. 11a). The large reduction in JulyAugust or in general from May to September is dominated by the reduction of precipitation in $\mathrm{NH}$ monsoon, including all three regional components: the North American, Asian, and northern African monsoons (Fig. 11b). During the austral summer, especially from November to December, the reduction of $\mathrm{NH}$ winter monsoon precipitation is minimal and the change in SH summer monsoon is small except the large reduction of South American monsoon. That is why the global monsoon precipitation reduction is minimal in November and December.

For the $\mathrm{NH}$, all regional monsoon precipitation changes quite consistently, with decreasing more from June to October (maximal in August), and less from December to May (Fig. 11b). On the other hand, the SH sub-monsoon precipitation changes differently, especially the Australian monsoon precipitation (Fig. 11c). The seasonal variation of southern African monsoon precipitation is small, which can be explained by the aforementioned different changes between the northern and southern part of this region. The South American winter monsoon precipitation is increased slightly from July to October, while the summer monsoon rainfall is decreased notably from January to March. The Australian monsoon precipitation has the largest changes, which is slightly increased in November and December (austral summer) and substantially decreased from April to September (austral fall-winter). The reduction of the fallwinter monsoon precipitation and the increase of the summer monsoon precipitation explains why the Australian annual mean precipitation is decreased, but its annual range and monsoon intensity are significantly increased (Fig. 11c). 
(a) JJAS mean precipitation rate

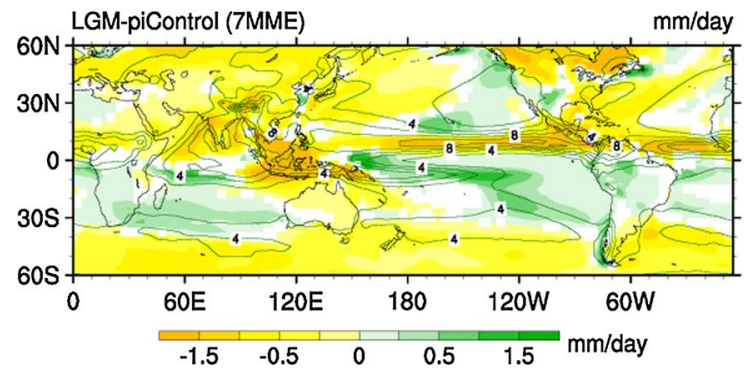

(b) DJFM mean precipitation rate

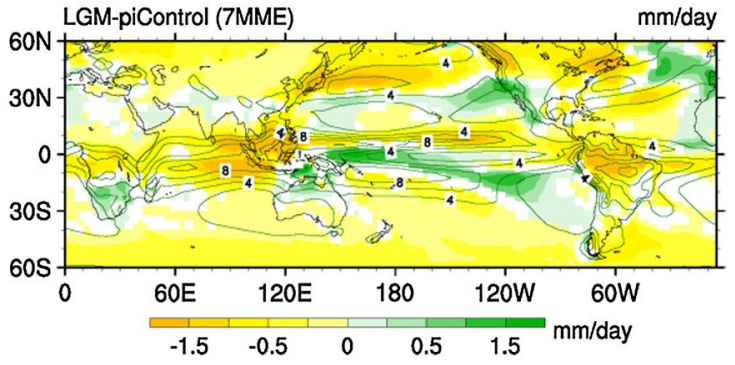

Fig. 10 Changes of the JJAS mean (a) and DJFM mean (b) precipitation. The difference between LGM and piControl is color-shaded, the climatology of piControl is in contour. Only the areas where the S2N ratio exceeds 1 are plotted

(a) GM precipitation

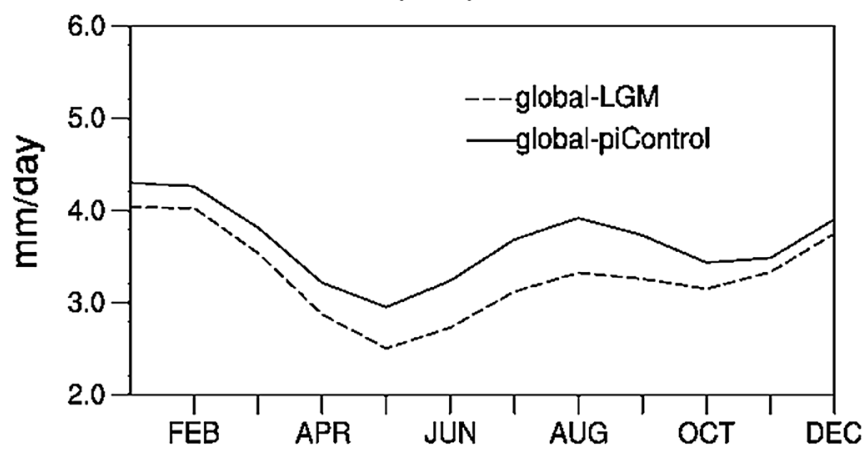

(b) NHM precipitation

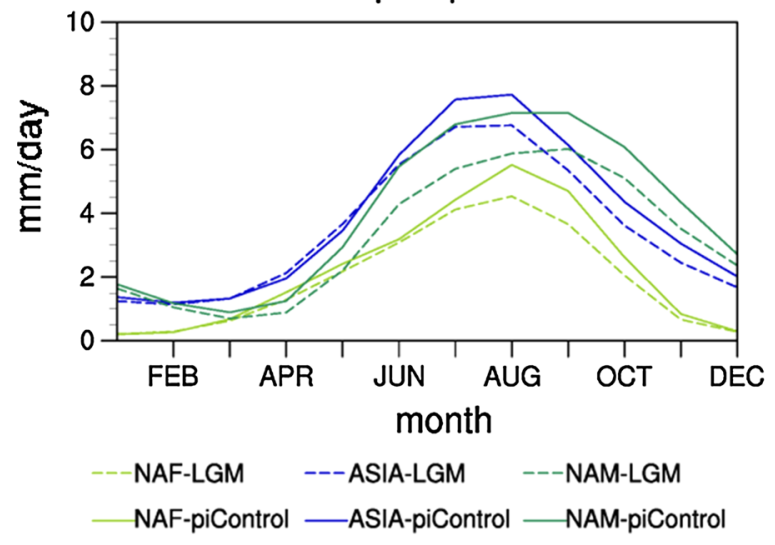

(c) SHM precipitation

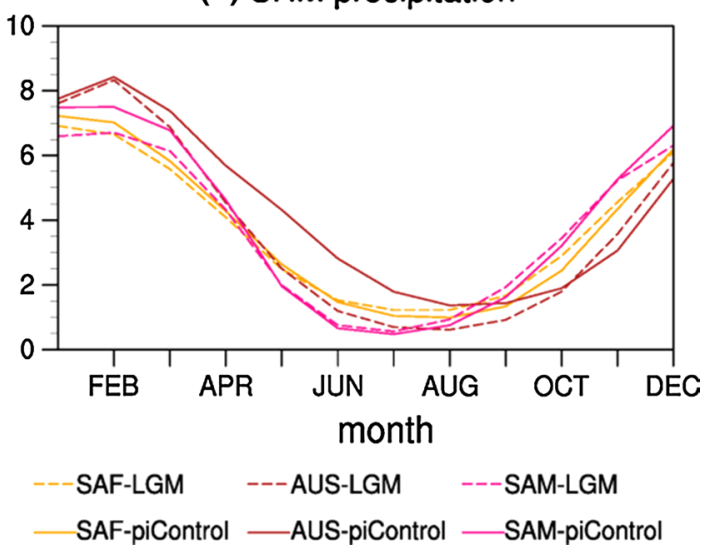

Fig. 11 Seasonal variation of a the global monsoon precipitation, $\mathbf{b}$ the regional monsoon precipitation over the NH and $\mathbf{c}$ the regional monsoon precipitation over the $\mathrm{SH}$

Although some uncertainties exist in the change of the SH monsoon precipitation from December to May, all the models and the 7MME are agreed in the change from June to November and the change of the $\mathrm{NH}$ monsoon precipitation seasonal distribution (Fig. 12).

While the general reduction for the monsoon precipitation can be attributed to the effects of greenhouse gas forcing and ice sheet forcing, the changes in the seasonal distributions of the GM and NH sub-monsoon precipitation are likely related to the insolation change (Fig. 13), i.e., the monsoon precipitation is reduced more when the insolation is reduced and less when the insolation increased. For the SH sub-monsoon precipitation, the seasonal distribution lags the seasonal change of the insolation for one or two seasons. The large heat capacity of the ocean regulates the lagged response of the $\mathrm{SH}$ monsoon precipitation to the 
(a) GM precipitation

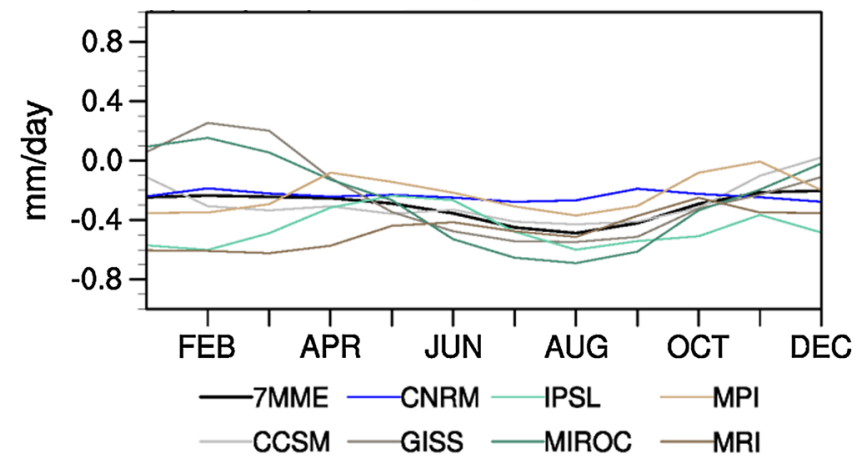

(b) NHM precipitation

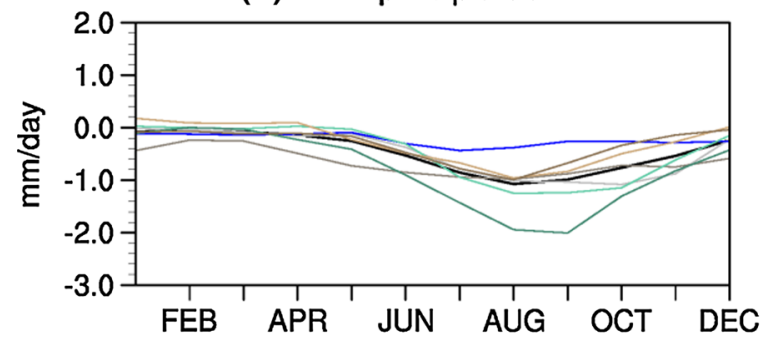

(c) SHM precipitation

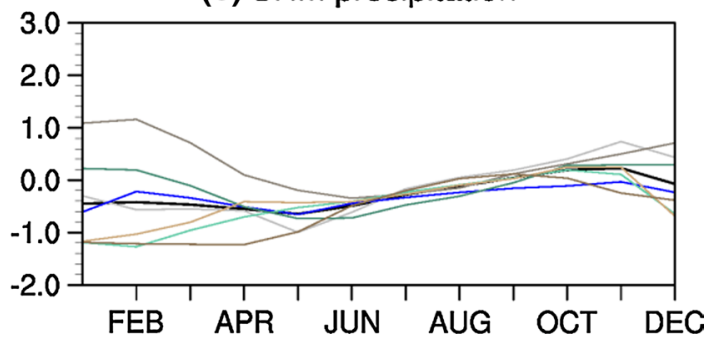

Fig. 12 Changes of the seasonal variation of a the global monsoon precipitation, $\mathbf{b}$ the NH monsoon precipitation and $\mathbf{c}$ the SH monsoon precipitation, derived from the 7MME (black line) and the individual models (color lines)

change of the insolation. The nearly simultaneous response in the $\mathrm{NH}$ monsoon suggests the ocean regulation effect is small, possibly due to the presence of the ice sheet effect but the precise reason needs further investigation.

\subsection{Changes of the Australian monsoon}

As mentioned above, the Australian monsoon shows a distinctive change amongst all components of regional monsoons. Here we zoomed into it to find out what was happening during the LGM.

The precipitation is reduced significantly during the austral autumn and winter, while is increased during the austral spring and summer (Fig. 14). The wetter local spring-summer and the drier local autumn-winter is consistent with the strengthened monsoon intensity (AR) and the enlarged monsoon domain as mentioned above. Among the 7 models, most of them simulate an increasing austral summer precipitation rate over land mass, except CNRM-CM5 and MPI-ESM-P. The increased local summer rainfall is consistent with the proxy reconstruction hypothesis resulted from a high austral summer insolation $\left(20^{\circ} \mathrm{S}\right.$, December $)$ (Ding et al. 2013).

The change of the Australian monsoon precipitation is related to the change in atmospheric circulation, for instance the convergence at $850 \mathrm{hPa}$ over the monsoon region, which is strengthened during the austral summer

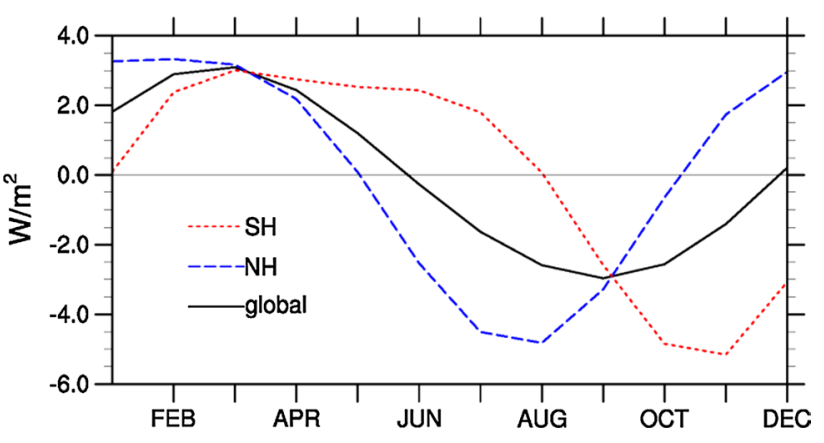

Fig. 13 Seasonal distribution of the global (black solid line), $\mathrm{NH}$ (blue dashed line) and $\mathrm{SH}$ (red dotted line) averaged insolation changes

(DJF) while weakened during the austral winter (JJA) (not shown). During DJF the westerly at $850 \mathrm{hPa}$ over the eastern Indian Ocean and the cross equatorial flow from South China Sea are strengthened (Fig. 15a). On the other hand, the JJA mean wind difference at $850 \mathrm{hPa}$ shows a divergence circulation over northern Australia (Fig. 15b). The changes of the seasonal wind and divergence fields explain the changes of the seasonal precipitation. 6 models (except MPI-ESM-P) simulate a strengthened DJF convergence over the land mass, 5 of which are agreed with the increased rainfall (except CNRM-CM5). 
(a) MAM mean precipitation rate

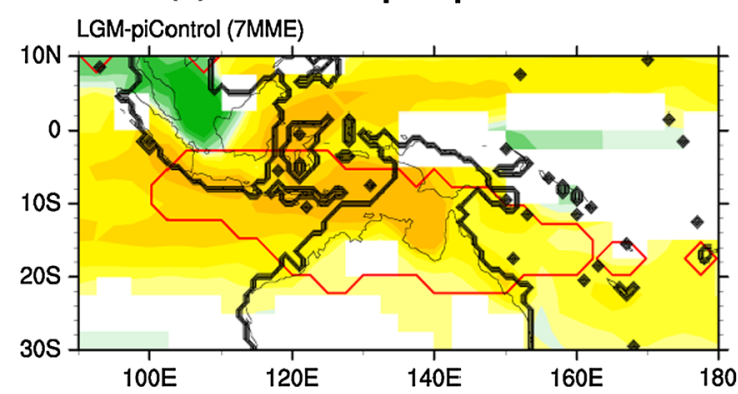

(c) SON mean precipitation rate

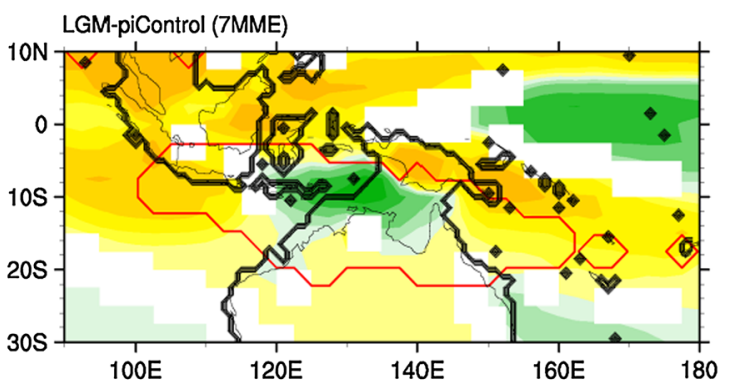

(b) JJA mean precipitation rate

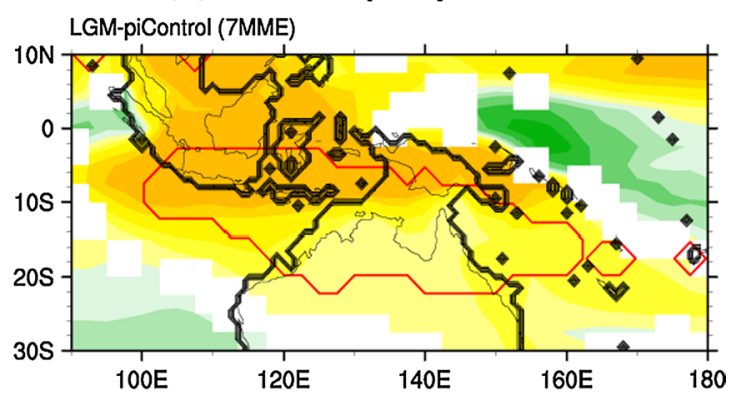

(d) DJF mean precipitation rate

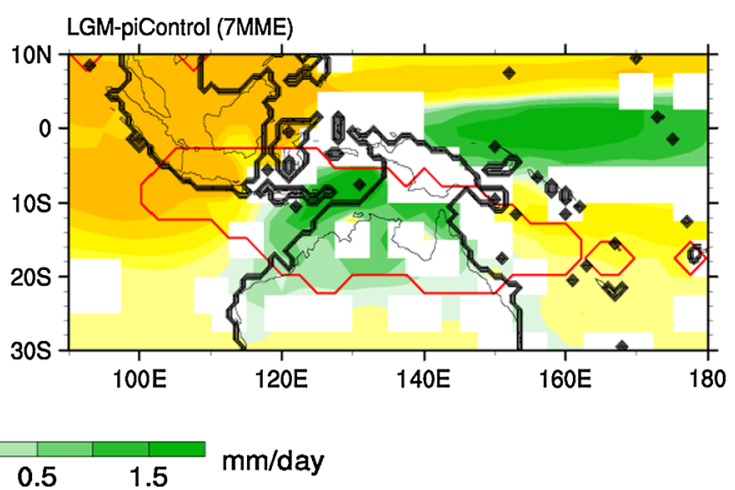

Fig. 14 Changes of the seasonal mean precipitation over the Australian monsoon region between the LGM and the piControl. a-d The MAM, JJA, SON and DJF mean, respectively. The contour in red denotes the GM domain derived from the merged CMAP-GPCP. The dark black lines enclose the coastline for the LGM. Only the areas where the $\mathrm{S} 2 \mathrm{~N}$ ratio exceeds 1 are plotted

convergence over the monsoon region. The zonal departure of the SST from the area average of $\left(30^{\circ} \mathrm{S}-30^{\circ} \mathrm{N}\right.$, $120^{\circ} \mathrm{E}-180^{\circ} \mathrm{E}$ ) (not shown) indicates a strengthened $\mathrm{NH}-$ SH asymmetry in boreal winter, which is also consistent with the change of the monsoon intensity.

\section{Conclusion and discussion}

By comparing the simulated climatological GM and precipitation from the LGM and the piControl experiments, we find the GM changes have the following features.

1. The global monsoon area is reduced during the LGM. However, the changes of the sub-monsoons are not uniform. The changes of the sub-monsoon domain over the $\mathrm{NH}$ are smaller than those over the SH. Regionally, the Asian, northern African and North American monsoon areas are reduced by $8.7,7.3$ and $4.3 \%$, respectively, with the southeastward shifting of the Asian and North American monsoon domain. In contrast, in the SH, the South American and southern African monsoon areas are reduced respectively by 15.6 and $13.4 \%$, while the Australian monsoon area is dramatically enlarged by $36.4 \%$. 
(a) DJF mean $850 \mathrm{hPa}$ wind
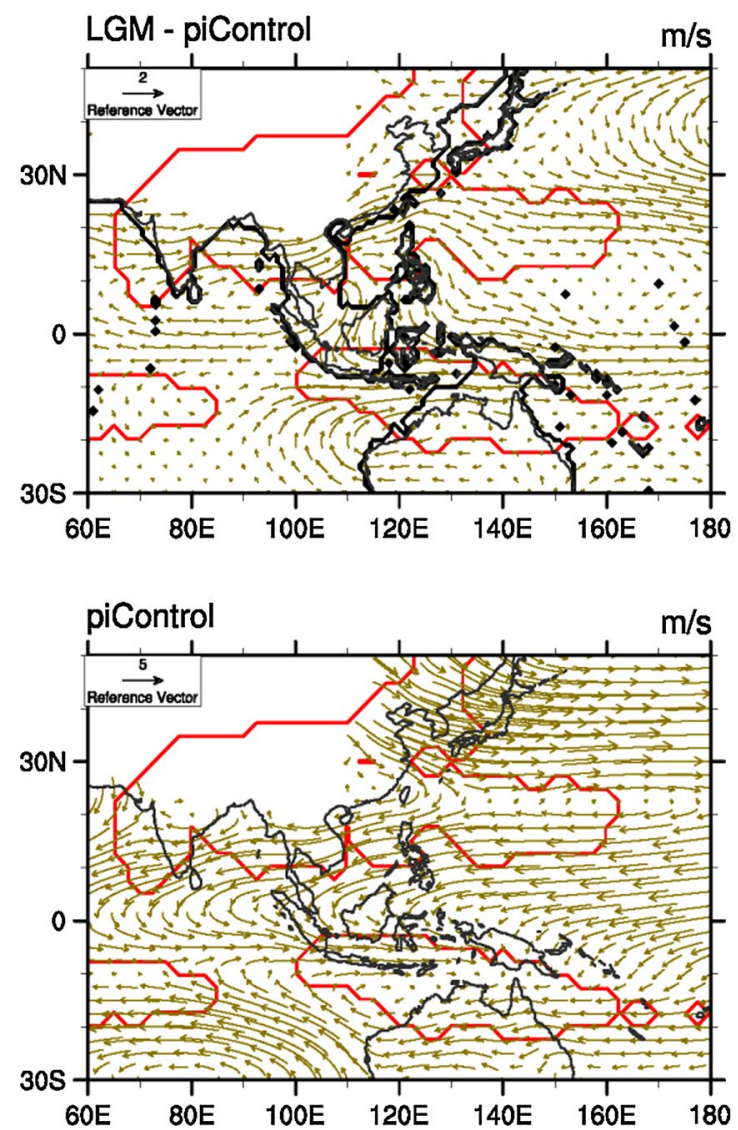

(b) JJA mean $850 \mathrm{hPa}$ wind
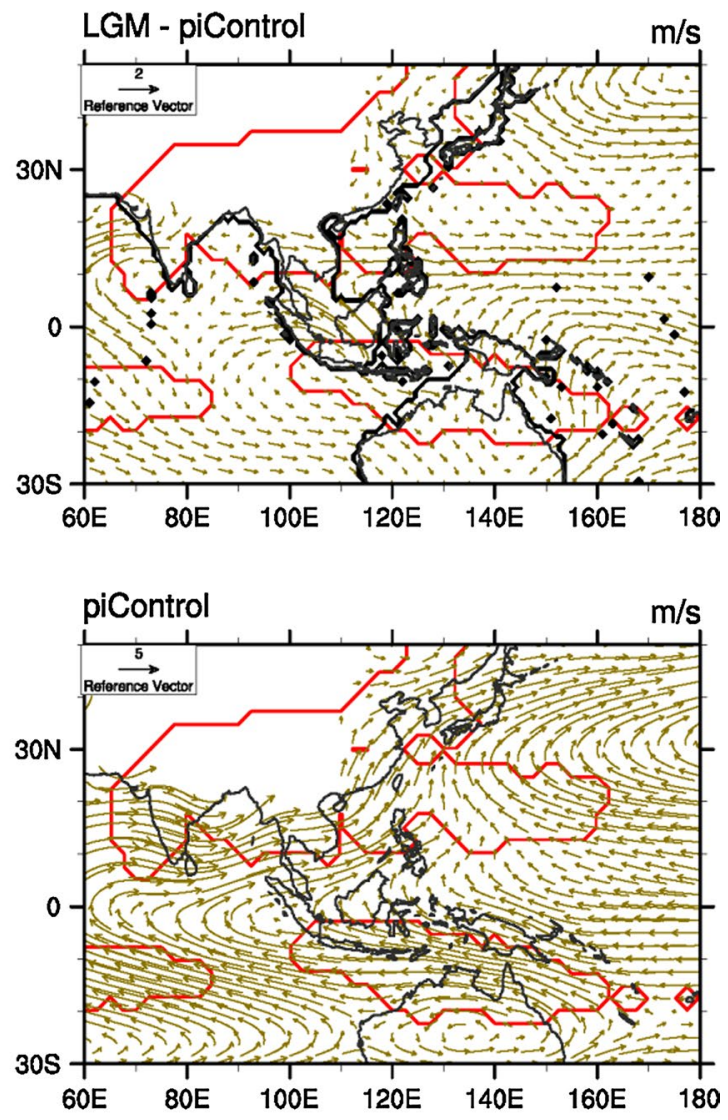

Fig. 15 Changes of the wind at $850 \mathrm{hPa}$ during DJF (a) and JJA (b) between the LGM and the piControl (upper panels), and the climatology during the piControl (lower panels). The dark black lines in the top panels enclose the coastline for the LGM

2. The monsoon intensity measured by the annual range of the precipitation is weakened over most part of the GM regions except the Australia and southern part of the southern Africa, mainly contributed by the decreasing of the local summer precipitation.

3. The GM precipitation is reduced generally. The global and the $\mathrm{NH}$ monsoon precipitation are reduced more during the local summer and less during the local winter, in accordance with the change in seasonal distribution of the insolation. While the seasonal variation of the $\mathrm{NH}$ monsoon precipitation is nearly in phase with the seasonal change of the insolation, the SH monsoon precipitation especially the Australian monsoon precipitation lags the seasonal distribution of the insolation change by one or two seasons.

4. The Australian monsoon is strengthened and the monsoon area is enlarged uniquely. The strengthened Australian monsoon intensity is contributed by the increased local summer rainfall and the decreased local winter rainfall. The increased austral summer (DJF) rainfall is mainly caused by the strengthened land- ocean thermal contrast in SON due to the sea level change during the LGM, which leads to a strengthened convergence in DJF.

The aforementioned changes in GM is a combined consequence of the four major factors: the reduced greenhouse gas concentration, the presence of the ice sheets over Eurasian and North American continent, the changes in the annual distribution of insolation caused by changing orbital forcing, and change of land configuration due to lowering sea level. Each of the four factors plays different roles in changing the GM and its regional component.

The weakening of annual mean global monsoon precipitation is primarily attributed to the lower greenhouse gas concentration in the atmosphere (Table 2) and the presence of the Fennoscandian and Laurentide ice sheets in the $\mathrm{NH}$ (Fig. 1, shading). Since the global annual mean insolation only changed $0.02 \mathrm{~W} / \mathrm{m}^{2}$, its contribution to global mean change is negligible. On the other hand, the $\mathrm{CO}_{2}$ radiative forcing (RF) was reduced by $2.22 \mathrm{~W} / \mathrm{m}^{2}$, which contributes significantly to the reduction of the global annual mean 


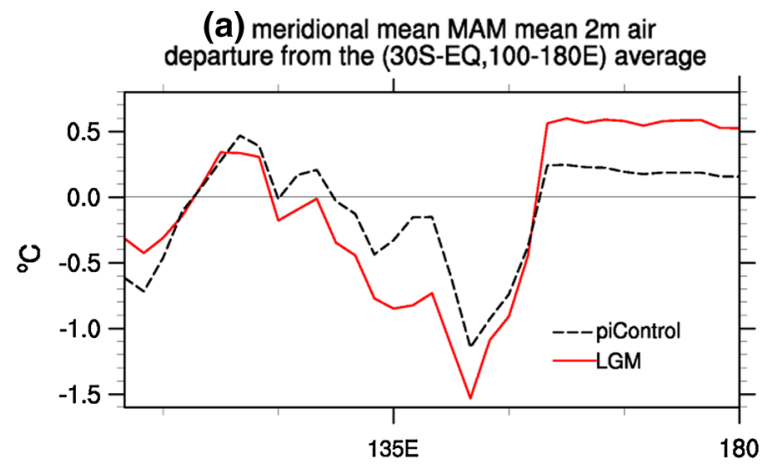

(c) meridional mean SON mean $2 \mathrm{~m}$ air departure from the (30S-EQ,100-180E) average

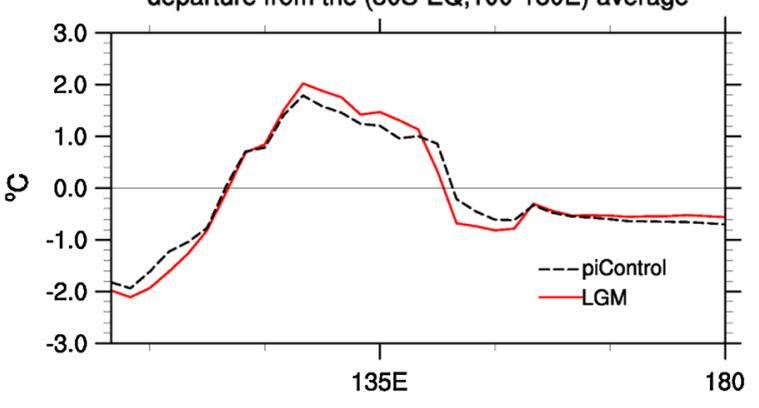

(b) meridional mean JJA mean $2 \mathrm{~m}$ air departure from the (30S-EQ,100-180E) average

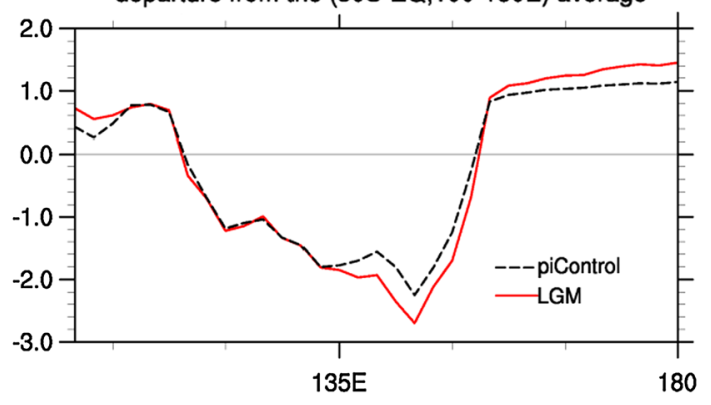

(d) meridional mean DJF mean $2 \mathrm{~m}$ air departure from the $(30 \mathrm{~S}-\mathrm{EQ}, 100-180 \mathrm{E})$ average

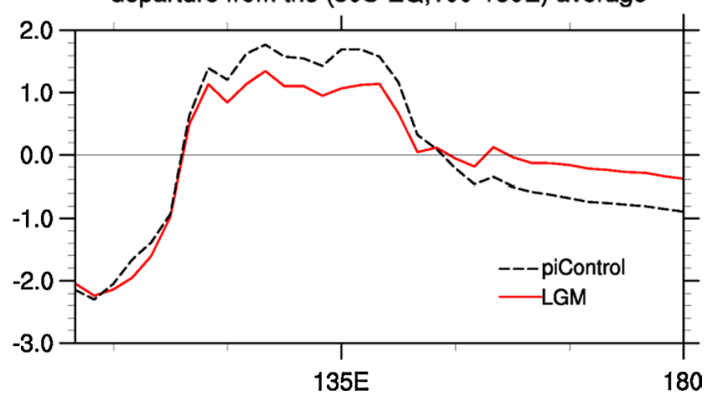

Fig. 16 Seasonal meridional mean of the $2 \mathrm{~m}$ air temperature during the LGM (red) and the piControl (black). a-d The MAM, JJA, SON and DJF mean, respectively

surface air temperature (GMT). Here the simplified formula is used to estimate the $\mathrm{RF}$ of the $\mathrm{CO}_{2}: \mathrm{RF}=5.35 \times \ln \left(\mathrm{CO}_{2} /\right.$ $\mathrm{CO}_{2}$ orig) (IPCC TAR 2001), where $\mathrm{CO}_{2}=185 \mathrm{ppm}$ and $\mathrm{CO}_{2}$ orig $=280 \mathrm{ppm}$. The result derived from the $7 \mathrm{MME}$ indicates that during LGM the GMT is decreased by $4.4^{\circ} \mathrm{C}$ with more over the $\mathrm{NH}\left(5.8{ }^{\circ} \mathrm{C}\right)$ and less over the $\mathrm{SH}$ $\left(3.0^{\circ} \mathrm{C}\right)$. A large portion of the reduction may be attributed to the greenhouse gas forcing change that is enhanced by the existence of the ice sheets.

A direct consequence of the global cooling is the reduction of the moisture content in the atmosphere. The Clausius-Clapeyron equation predicts a $7 \%$ reduction in saturation humidity per degree of global cooling in the present day climate. The reduction of the moisture content in the atmospheric column follows the reduction of the saturation humidity closely. Such a large reduction in available moisture in the atmosphere can reduce the monsoon precipitation substantially assuming the atmospheric circulation unchanged. This so-called "dry-gets-drier" mechanism (Held and Soden 2006; Wang et al. 2012; Lee and Wang 2014) is certainly an essential explanation to the weakening of the global mean monsoon precipitation.

Note also that the presence of the Fennoscandian and Laurentide ice sheets in the NH play important role in the LGM climate change. Chiang and Bitz (2005) found that the ITCZ would shift southwards due to a wind-evaporation-SST feedback induced by the anomalous ice. Donohoe et al. (2013) also found a southward shift of the ITCZ in the LGM. As stated in Sect. 4.1, the southward shifting of the ITCZ is consistent with the shift of the NH monsoon domain. We found that the two presented ice sheets during the LGM trigger two cyclonic difference circulations at mid-high level (500 and $200 \mathrm{hPa}$, not shown) over the eastern landmass during JJA, especially over the eastern North America. The strengthened northwest flows over the midhigh latitude to the East Asian and North American monsoon regions push the two monsoon domains shift southward and eastward.

Ueda et al. (2011) found that for the mature period of the Asian summer monsoon, the ice sheet effect emerged to cool the atmospheric temperatures throughout the troposphere and might weaken the summer monsoon circulation. Kim (2004) simulated the effect of lower $\mathrm{CO}_{2}$ concentration and ice sheet topography on the LGM climate separately. They found that the surface cooling was substantially larger in the $\mathrm{NH}$ than in the $\mathrm{SH}$ for both cases and was more pronounced in the ice sheet topography case. In this study, we find that the changes in seasonal $\mathrm{NH}-\mathrm{SH}$ thermal contrast may induce the strengthened Australian monsoon. It may also be attributed to the lower greenhouse gas concentration and the presence of the ice sheets during LGM.

The change of the insolation forcing, although does not affect the mean GM, it may contributes to the seasonal 
distribution of the GM thus change the annual range and the GM intensity. The GM is a response of atmosphere-landocean coupled system to the annual variation of solar radiation (Wang and Ding 2008). During the LGM, for both the $\mathrm{NH}$ and $\mathrm{SH}$, the hemispheric insolation is increased during the local winter while decreased during the local summer (Fig. 13), especially over the NH, which means the annual variation of solar radiation is weakened during the LGM. The annual variation of the global insolation is reduced by $3.85 \mathrm{~W} / \mathrm{m}^{2}$, likely leading to a weakened GM intensity. How far would the insolation change influence the GM? Numerical experiments with changing orbital forcing only might provide a clue. This calls for further study.

For the Australian monsoon region, the land-sea mask is changed during the LGM because of the change of sea level, and the Maritime Continent and Australia becomes an expanded continent, especially over the equatorial regions (Fig. 1, red line). The change of the land-ocean thermal contrast is quite on the contrary between the Australian monsoon region and the southern African and South American monsoon regions. The strengthened land-ocean thermal contrast between the Australia and its adjacent Pacific Ocean favors the Australian monsoon precipitation and therefore enlarges the monsoon domain. For the other two monsoon regions over the SH, the southern African and the South American, the weakened land-ocean thermal contrast leads to the reduced monsoon precipitation and the monsoon domain.

It is important to point out that the qualitative discussion here cannot assess the quantitative contributions of the each factor to the monsoon changes. More sensitivity experiments are needed for understanding the relative contributions of these four factors to changes of the global, $\mathrm{NH}$ and $\mathrm{SH}$ monsoons, as well as regional monsoons.

Acknowledgments We acknowledge the reviewers and Prof. Zhu AX for the constructive comments helping to clarify and improve the paper. This work is jointly supported by the National Basic Research Program (Grant No. 2015CB953804), the Strategic and Special Frontier Project of Science and Technology of the Chinese Academy of Sciences (Grant No. XDA05080800), the National Natural Science Foundation of China (Grant Nos. 41302137, 41371209 and 41420104002), and A Project Funded by the Priority Academic Program Development of Jiangsu Higher Education Institutions (PAPD). Bin Wang acknowledge support from the National Research Foundation (NRF) of Korea through a Global Research Laboratory (GRL) grant of the Korean Ministry of Education, Science and Technology (MEST, \#2011-0021927) and the support from China-US Atmosphere-Ocean Research Center. We also acknowledge the World Climate Research Programme's Working Group on Coupled Modelling, which is responsible for CMIP, and we thank the climate modeling groups (listed in Table 1 of this paper) for producing and making available their model output. For CMIP the US Department of Energy's Program for Climate Model Diagnosis and Intercomparison provides coordinating support and led development of software infrastructure in partnership with the Global Organization for Earth System Science Portals. This is the Earth System Modeling Center (ESMC) Contribution Number 065.
Open Access This article is distributed under the terms of the Creative Commons Attribution 4.0 International License (http://creativecommons.org/licenses/by/4.0/), which permits unrestricted use, distribution, and reproduction in any medium, provided you give appropriate credit to the original author(s) and the source, provide a link to the Creative Commons license, and indicate if changes were made.

\section{References}

Braconnot P, Otto-Bliesner B, Harrison S et al (2007a) Results of PMIP2 coupled simulations of the Mid-Holocene and Last Glacial Maximum-part 1: experiments and large-scale features. Clim Past 3:261-277

Braconnot P, Otto-Bliesner B, Harrison S et al (2007b) Results of PMIP2 coupled simulations of the Mid-Holocene and Last Glacial Maximum - part 2: feedbacks with emphasis on the location of the ITCZ and mid- and high latitudes heat budget. Clim Past 3:279-296

Braconnot P, Harrison S, Otto-Bliesner B et al (2011) The Paleoclimate Modeling Intercomparison Project contribution to CMIP5. CLIVAR Exch 56(16):15-19

Braconnot P, Harrison S, Kageyama M et al (2012) Evaluation of climate models using palaeoclimatic data. Nat Clim Change 2:417424. doi:10.1038/nclimate 1456

Chabangborn A, Brandefelt J, Wohlfarth B (2014) Asian monsoon climate during the Last Glacial Maximum: palaeo-data-model comparisons. Boreas 43(1):220-242

Chavaillaz Y, Codron F, Kageyama M (2013) Southern westerlies in LGM and future (RCP4.5) climates. Clim Past 9:517-524

Chen HP, Sun J (2013) How large precipitation changes over global monsoon regions by CMIP5 models? Atmos Ocean Sci Lett 6(5):306-311. doi:10.3878/j.issn.1674-2834.13.0002

Chiang JCH, Bitz CM (2005) Influence of high latitude ice cover on the marine intertropical convergence zone. Clim Dyn 25(5):477-496

Christensen JH, Kumar KK, Aldrian E et al (2013) Climate phenomena and their relevance for future regional climate change. In: Stocker TF, Qin D, Plattner G-K, Tignor M, Allen SK, Boschung J, Nauels A, Xia Y, Bex V, Midgley PM (eds) Climate change 2013: the physical science basis. Contribution of working group I to the fifth assessment report of the intergovernmental panel on climate change. Cambridge University Press, Cambridge

DiNezio PN, Clement A, Vecchi GA et al (2011) The response of the Walker circulation to Last Glacial Maximum forcing: implications for detection in proxies. Paleoceanography. doi:10.1029/2 010PA002083

Ding X, Bassinot F, Guichard F et al (2013) Indonesian throughflow and monsoon activity records in the Timor Sea since the Last Glacial Maximum. Mar Micropaleontol 101:115-126

Donohoe A, Marshall J, Ferreira D, Mcgee D (2013) The relationship between ITCZ location and cross-equatorial atmospheric heat transport: from the seasonal cycle to the Last Glacial Maximum. J Clim 26:3597-3618

Harrison SP, Bartlein PJ, Brewer S et al (2014) Climate model benchmarking with glacial and mid-Holocene climates. Clim Dyn 43(3-4):671-688

Held IM, Soden BJ (2006) Robust responses of the hydrological cycle to global warming. J Clim 19:5686-5699. doi:10.1175/ JCLI3990.1

Hsu PC, Li T, Murakami H et al (2013) Future change of the global monsoon revealed from 19 CMIP5 models. J Geophys Res Atmos 118:1247-1260. doi:10.1002/jgrd.50145 
Huffman GJ, Adler RF, Bolvin DT et al (2009) Improving the global precipitation record: GPCP Version 2.1. Geophys Res Lett 36:L17808

IPPC (2001) Climate change 2001: the scientific basis. In: Houghton JT, Ding DJ, Griggs M, Noguer M, van der Linden PJ, Dai X, Maskell K, Johnson CA (eds) Contribution of working group I to the third assessment report of the intergovernmental panel on climate change. Cambridge University Press, Cambridge

Jiang D, Lang X (2010) Last Glacial Maximum East Asian monsoon: results of PMIP simulations. J Clim 23:5030-5038

Kim SJ (2004) The effect of atmospheric $\mathrm{CO}_{2}$ and ice sheet topography on LGM climate. Clim Dyn 22:639-651

Kim HJ, Wang B, Ding QH (2008) Assessing the global monsoon simulated by the CMIP3 coupled climate models. J Clim 21:5271-5294

Kitoh A, Yukimoto S, Noda A et al (1997) Simulated changes in the Asian summer monsoon at times of increased atmospheric $\mathrm{CO}_{2}$. J Meteorol Soc Jpn 75:1019-1031

Kitoh A, Endo H, Kumar KK et al (2013) Monsoons in a changing world regional perspective in a global context. J Geophys Res Atmos 118(8):3053-3065. doi:10.1002/jgrd.50258

Laine A, Kageyama M, Salas-Melia D et al (2009) Northern hemisphere storm tracks during the Last Glacial Maximum in the PMIP2 ocean-atmosphere coupled models: energetic study, seasonal cycle, precipitation. Clim Dyn 32:593-614

Leduc G, Vidal L, Tachikawa K et al (2007) Moisture transport across Central America as a positive feedback on abrupt climatic changes. Nature 445:908-911

Lee JY, Wang B (2014) Future change of global monsoon in the CMIP5. Clim Dyn 42:101-119

Li C, Battisti DS (2008) Reduced Atlantic Storminess during Last Glacial Maximum: evidence from a coupled climate model. J Clim 21:3561-3579

Li H, Zhou T, Li C (2010) Decreasing trend in global land monsoon precipitation over the past 50 years simulated by a coupled climate model. Adv Atmos Sci 27(2):285-292

Liu J, Wang B, Ding Q et al (2009) Centennial variations in Global monsoon precipitation in the last Millennium: results from ECHO-G model. J Clim 22:2356-2371

Liu J, Wang B, Yim SY et al (2012) What drives the global summer monsoon over the past millennium? Clim Dyn 39:1063-1072

Otto-Bliesner BL, Schneider R, Brady EC et al (2009) A comparison of PMIP2 model simulations and the MARGO proxy reconstruction for tropical sea surface temperatures at Last Glacial Maximum. Clim Dyn 32:799-815

Peltier WR (2009) Closure of the budget of global sea level rise over the GRACE Era: the importance and magnitudes of the required corrections for global glacial isostatic adjustment. Quat Sci Rev 28:1658-1674

Rojas M (2013) Sensitivity of Southern Hemisphere circulation to LGM and $4 \times \mathrm{CO}_{2}$ climates. Geophys Res Lett 40(5):956-970

Rojas M, Moreno P, Kageyama M et al (2009) The Southern Westerlies during the Last Glacial Maximum in PMIP2 simulations. Clim Dyn 32:525-548

Taylor KE, Stouffer RJ, Meehl GA (2012) An overview of CMIP5 and the experiment design. Bull Am Meteorol Soc 93:485-498. doi:10.1175/BAMS-D-11-00094.1

Ueda H, Kuroki H, Ohba M et al (2011) Seasonally asymmetric transition of the Asian monsoon in response to ice age boundary conditions. Clim Dyn 37:2167-2179

Wang PX (2009) Global monsoon in a geological perspective. Chin Sci Bull 54(7):1113-1136

Wang B, Ding Q (2006) Changes in global monsoon precipitation over the past 56 years. Geophys Res Lett 33:L06711. doi:10.102 9/2005GL025347

Wang B, Ding Q (2008) Global monsoon: dominant mode of annual variation in the tropics. Dyn Atmos Ocean. doi:10.1016/j. dynatmoce.2007.05.002

Wang B, Kim HJ, Kikuchi K et al (2011) Diagnostic metrics for evaluation of annual and diurnal cycles. Clim Dyn 37:941-955. doi:10.1007/s00382-010-877-0

Wang B, Liu J, Kim HJ et al (2012) Recent change of the global monsoon precipitation (1979-2008). Clim Dyn 39:1123-1135

Wang B, Liu J, Kim HJ et al (2013a) Northern Hemisphere summer monsoon intensified by mega-El Nino-southern oscillation and atlantic multidecadal oscillation. PNAS 110(14):5347-5352. doi:10.1073/pnas.1219405110

Wang T, Liu Y, Huang W (2013b) Last Glacial Maximum sea surface temperatures: a model-data comparison. Atmos Ocean Sci Lett 6(5):233-239

Xie PP, Arkin PA (1997) Global precipitation: a 17-year monthly analysis based on gauge observations, satellite estimates, and numerical model outputs. Bull Am Meteorol Soc 78:2539-2558

Yanase W, Abe-Ouchi A (2007) The LGM surface climate and atmospheric circulation over East Asia and the North Pacific in the PMIP2 coupled model simulations. Clim Past 3:439-451

Zhou T, Zhang L, Li H (2008a) Changes in global land monsoon area and total rainfall accumulation over the last half century. Geophys Res Lett 35:L16707. doi:10.1029/2008GL034881

Zhou T, Yu R, Li H et al (2008b) Ocean forcing to changes in global monsoon precipitation over the recent half century. J Clim 21:3833-3852. doi:10.1175/2008JCLI2067.1 